\title{
Metal Complexes in Medicine: An Overview and Update from Drug Design Perspective
}

\author{
Ravinderpal Kour Sodhi* and Satya Paul \\ Department of Chemistry, University of Jammu, Jammu-180 006, India
}

Submission: March 18, 2019; Published: June 17, 2019

"Correspondence Author: Ravinderpal Kour Sodhi, Department of Chemistry, University of Jammu, Jammu-180 006, India

\begin{abstract}
Metals are essential cellular components selected by nature to function in several indispensable biochemical processes for living organisms. Transition metal complexes are important in catalysis, materials synthesis, photochemistry, and biological systems. Medicinal inorganic chemistry can exploit the unique properties of metal ions for the design of new drugs. The use of metals and their salts for medicinal purposes has been present throughout history. With the advancement in the field of inorganic chemistry the role of transition metal complexes as therapeutic compounds is becoming increasingly important. Recent advances in inorganic chemistry have made possible formation of number of transition metal complexes with organic ligand of interest, which can be used as therapeutic agent. This review illustrates the role of metals and the recent progress in the field of medicinal bioinorganic chemistry with new approaches to the design of innovative metal-based drugs and their application.
\end{abstract}

Keywords: Metal Complexes, Metal-based Drugs, Medicinal Chemistry, Applications.

\section{Introduction}

Metal ions play many critical functions in humans. Deficiency of some metal ions can lead to disease like pernicious anaemia resulting from iron deficiency, growth retardation arising from insufficient dietary zinc, and heart disease in infants owing to copper deficiency. The ability to understand at the molecular level and to treat diseases caused by inadequate metal-ion function constitutes an important aspect of medicinal bioinorganic chemistry. Metal ions are required in biology for their role as pharmaceuticals as well as diagnostic agents. Metals are endowed with unique characteristics that include redox activity, variable coordination modes, and reactivity towards organic substrates. Due to their reactivity, metals are tightly regulated under normal conditions and aberrant metal ion concentrations are associated with various pathological disorders, including cancer. For these reasons, coordination complexes, either as drugs or pro-drugs, become very attractive probes in medicinal chemistry. In nature, many biological systems make extensive use of metal ions, such as zinc and copper, which play critical roles in the normal functioning of organisms [1]. Transition metals such as copper, iron, and manganese, among others, are involved in multiple biological processes, from electron transfer to catalysis to structural roles, and are frequently associated with active sites of proteins and enzymes [1]. However, deregulations of some of these essential metals during normal biochemical processing have been implicated in the development of various pathological disorders, such as cancer [2]. These cellular functions only require the "trace metals" in miniscule but tightly regulated amounts. Research has shown significant progress in utilization of transition metal complexes as drugs to treat several human diseases. Transition metals exhibit different oxidation states and can interact with a few negatively charged molecules. These properties of transition metals led to the development of metalbased drugs with promising pharmacological application and unique therapeutic opportunities. The advances in inorganic chemistry provide better opportunities to use metal complexes as therapeutic agents.

The use of transition metal complexes as therapeutic compounds has become more and more pronounced. These complexes offer a great diversity in their action such as; antiinflammatory, anti-infective and anti-diabetic compounds. Considerable efforts are made for the development of transition metal complexes as drugs. Beside several limitations and side effects, transition metal complexes are still the most widely used chemotherapeutic agents and make a large contribution to medicinal therapeutics [3]. 


\section{Cancer Therapy \& Oncology International Journal}

\section{Properties of Metal Complexes and Metal-Based Compounds}

Metal complexes and metal-based compounds possess the ability to coordinate with ligands in a three-dimensional configuration, thereby allowing functionalization of groups that can be shaped to defined molecular targets [4].

i. Charge Variation: In aqueous solution, metal ions exist as positively charged species. Depending on the existing coordination environment, the charge can be modified to generate species that can be cationic, anionic or neutral. Most importantly, they form positively charged ions in aqueous solution that can bind to negatively charged biological molecules [4].

ii. Structure and Bonding: Metal complexes can aggregate to a wide range of coordination geometries that give them unique shapes. The bond length, bond angle and coordination site vary depending on the metal and its oxidation state. In addition to this, metal-based complexes can be structurally modified to a variety of distinct molecular species that confer a wide spectrum of coordination numbers and geometries [4-6]

iii. Metal-Ligand Interaction: Different forms of metalligand interaction exists; however, these interactions usually lead to the formation of complexes that are unique from those of individual ligands or metals. The thermodynamic and kinetic properties of metal-ligand interactions influence ligand exchange reactions. The ability of metals to undergo these reactions offers a wide range of advantages to the metals to interact and coordinate with biological molecules [4].

iv. Lewis Acid Properties: Characterized by high electron affinity, most metal ions can easily polarize groups that are coordinated to them, thus facilitating their hydrolysis $[4,7]$.

v. Redox Activity: Many transition metals tend to undergo oxidation and reduction reactions [7]. The oxidation state of these metals is an important consideration in the design of the coordination compound. In biochemical redox catalysis, metal ions often serve to activate coordinated substrates and to participate in redox-active sites for charge accumulation.

vi. Partially Filled D Shell: For transition metals, the variable number of electrons in the $d$ shell or $f$ shell (for lanthanides) influences the electronic and magnetic properties of transition metal complexes [7].

\section{Metals in Medicine}

Metal containing drugs are important for a few medical applications including diagnosis and treatment.

\section{Metals Application}

A. Platinum: Platinum based compounds have been shown to specifically affect Head and Neck tumors. These coordination complexes are thought to act cross-link DNA in tumor cells

B. Gold: Gold salt complexes have been used to treat Rheumatoid Arthritis. The gold salts are believed to interact with albumin and eventually be taken up by immune cells, triggering anti-mitochondrial effects and eventually cell apoptosis.

C. Lithium: Li2CO3 can be used to treat prophylaxis of Manic-Depression behaviour.

D. Zinc: Zinc can be used topically to heal wounds. $\mathrm{Zn}^{2+}$ can be used to treat the Herpes virus.

E. Silver: Silver has been used to prevent infection at the burn site for burn wound patients.

F. Gold, Silver, Copper: Phosphine ligand compounds containing gold, silver, and copper have Anti-Cancer properties

G. Lanthanum: Lanthanum Carbonate often used under the trade name Fosrenol is used as a phosphate binder in patients suffering from Chronic Kidney disease.

H. Bismuth: Bismuth subsalicylate is used as an antacid.

I. Platinum, Titanium, Vanadium, Iron: cis DDP (cisdiaminedichoroplatinum), titanium, vanadium, and iron have been shown to react with DNA specifically in tumour cells to treat patients with Cancer.

J. Barium: X-ray diagnosis

K. Gadolinium, Manganese: Magnetic resonance imaging

L. Mercury: Antiseptic and diuretic

\section{Some Important Metal-Based Drugs}

NAMI-A and KP1019 are two potential ruthenium drugs possessing antitumor behaviours

\section{Recent Advancements in the Field of Medicinal Chemistry Involving Metal-Based Drugs}

Soon after the entry of cisplatin into the clinic a wide range of related compounds were prepared and evaluated. Neutral Pt (II) complexes with a square-planar geometry, including two ciscoordinated leaving groups, were defined as critical structural features for anticancer activity [8]. Gold (III) complexes have long been sought for anti-cancer treatments. Many gold (III) complexes have displayed interesting anticancer potencies, but their medicinal applications have always been hampered by their poor stability in solution [9]. Che et al. [10] prepared a series of physiologically stable gold (III) complexes which possess significant in vitro and in vivo anti-cancer activities. Research showed that the [Au (TPP)] Cl (H2TPP = tetraphenylporphyrin) complex exhibited potent in vitro anticancer activities toward a panel of cancer cell lines (Figure 1). 
<smiles>N[C@@H]1C[C@@H](Cl)[C@H](Cl)[C@@H]1Cl</smiles>

Cisplatin<smiles>O=C1O[Bi](O)Oc2ccccc21</smiles>

\section{Bismuth subsalicylate}<smiles>O=C(O)c1ccccc1-c1c2cc(Br)c(=O)cc-2oc2c([13CH]([O-])O)c(O)c(Br)cc12</smiles>

Merbromin

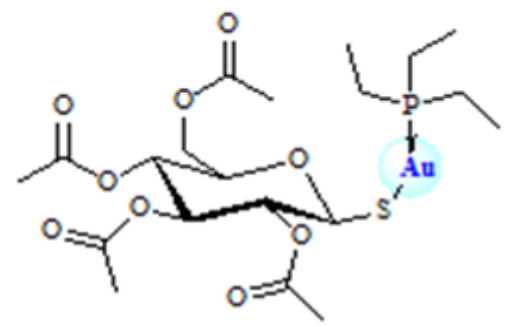

Auranofin

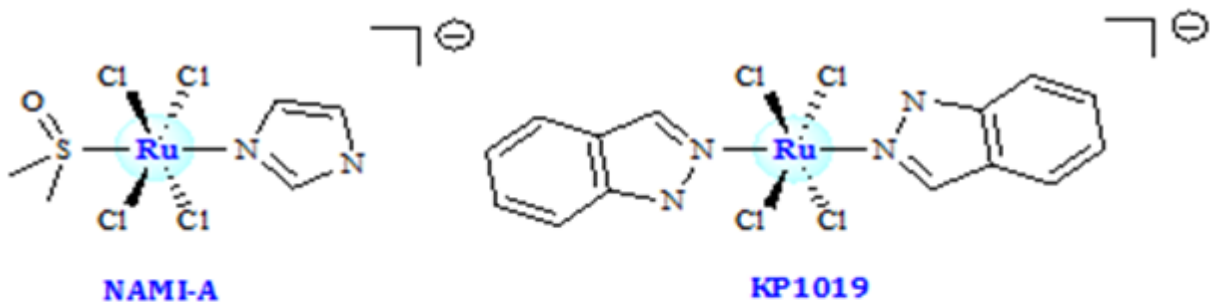

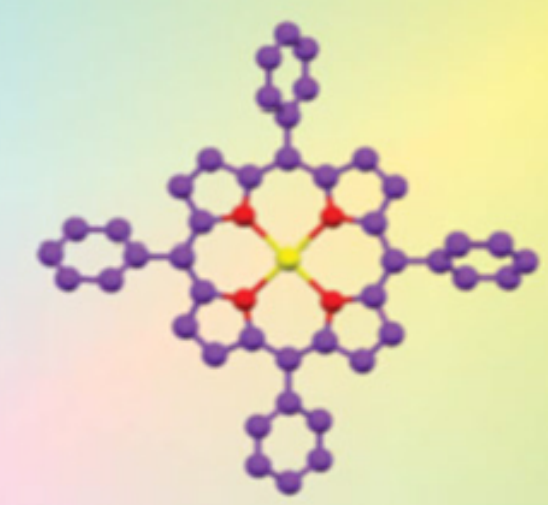

Figure 1: X-Ray crystal structure of [Au III(TPP)]+.

The redox properties of both metals and ligands in transition metal complexes offer unusual routes for new mechanisms of anticancer therapy. Metal complexes can introduce artificial reductive and oxidative stress into cancer cells, including behaviour as photoactivatable agents and catalysts. More recently, novel Co III, Fe III, Pt IV, Ru (III/II), Os II, and Ir III complexes have been reported to exhibit redox-mediated anticancer activity (Figure 2) [11]. 
(a)

$\underbrace{\mathrm{C} / \mathrm{Nu} / \mathrm{Cl}}_{-\mathrm{NH}}$ (b)

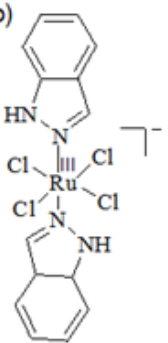

(c)

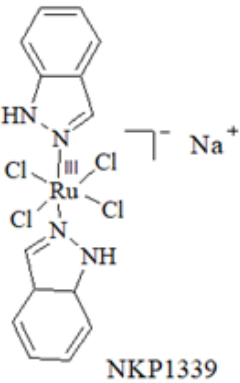

NAMI-A

KP1019

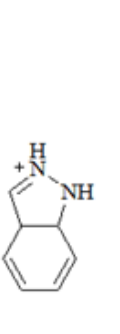

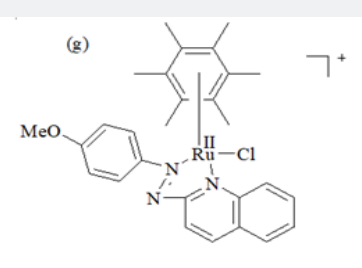

RAS-1H<smiles>Cl[R17]1(c2ccccc2-c2ccccc2)NCCN1</smiles>

RM175<smiles>Cc1ccc(C(C)C)cc1[R1](Cl)(Cl)[P+]12CN3CN(CN(C3)[C@H]1C[I+])C2</smiles>

RAPTA-C

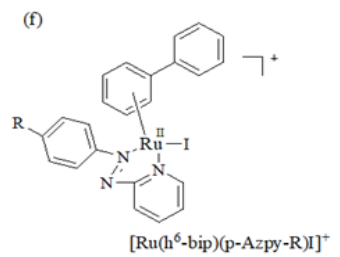

$\mathrm{R}=\mathrm{N}\left(\mathrm{CH}_{3}\right)_{2} \mathrm{OH}$ (d)

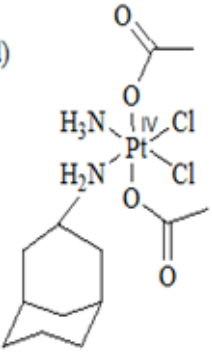

RAS-1T

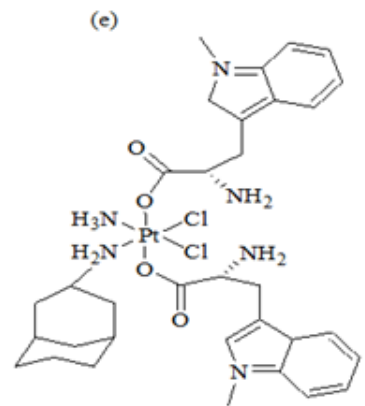

(a)

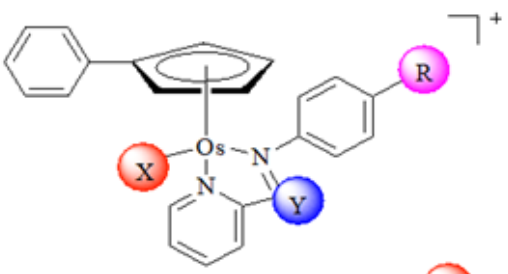

(b)

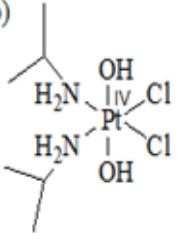

(c)

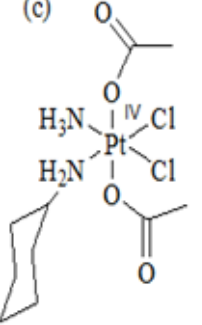<smiles>CCCCCCCCCCCCCCCCNC(=O)OP(N)(N)(Cl)Cl</smiles>

(b)
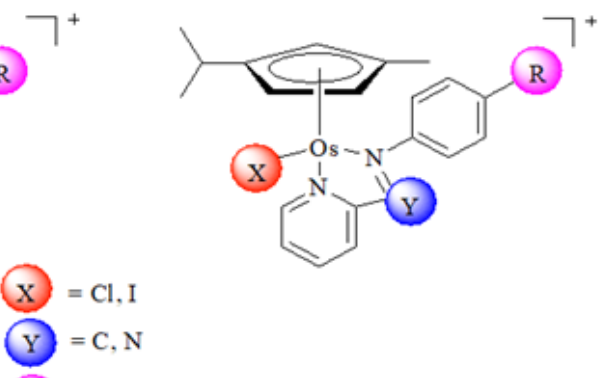

$\mathrm{Y}=\mathrm{C}, \mathrm{N}$

$\mathrm{R}=\mathrm{OH}, \mathrm{NMe}_{2}$

Figure 2: Some $\mathrm{Co}, \mathrm{Ru}, \mathrm{Pt}$ and Os metal complexes exhibiting redox mediated anticancer activity. 


\section{Cancer Therapy \& Oncology International Journal}

Many metal complexes have been synthesized and evaluated to overcome the problems of painful insulin injection and side effects for type 1 /type 2 diabetes mellitus. Although, chromium [12], manganese [13], molybdenum [14], copper [15,16], cobalt [17], zinc [18] and vanadium ions $[19,20]$ have been reported to exhibit insulin-mimetic or enhancing properties in vitro and in vivo, vanadium seems to be the most promising one, especially when coordinated to certain organic ligands. The insulin like effect of vanadium salts on cells $[21,22]$ and diabetic animals [22-24] has stimulated research into the clinical use of vanadium compounds as insulin mimetic (Figure 3).

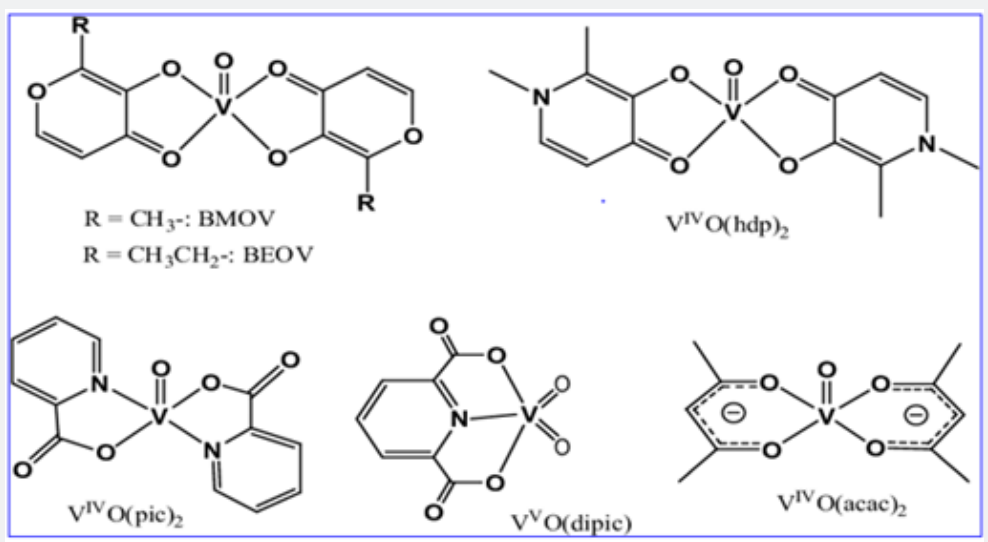

Figure 3: Structures of some insulin mimetic Vanadium complexes.

Gallium (III) complexes present a special activity in anticancer therapy due to the analogy of the Ga (III) ion with the Fe (III) ion in ionic radius, electron affinity, electro-negativity, coordination geometry, and Lewis base affinity. Di-nuclear and tetra-nuclear organometallic gallium (III) compounds containing heterocyclic thiolato ligands were synthesized by Gomez-Ruiz et al (Figure 4). These compounds were synthesized by a simple protonolysis reaction of trimethylgallium and the thiol group of mercapto-substituted imidazole, tetrazole, benzothiazole or phenyl-oxadiazol heterocycles. The heterocyclic thiolate polynuclear gallium (III) derivatives showed improved anticancer activity [25]. Alzheimer's disease (AD) is currently an incurable neurodegenerative disorder that affects millions of people around the world. Various Amyloid $\beta$-targeted metal complexes have exhibited promising potential as anti-AD agents due to their fascinating physicochemical properties over the past two decades (Figure 5) [26].

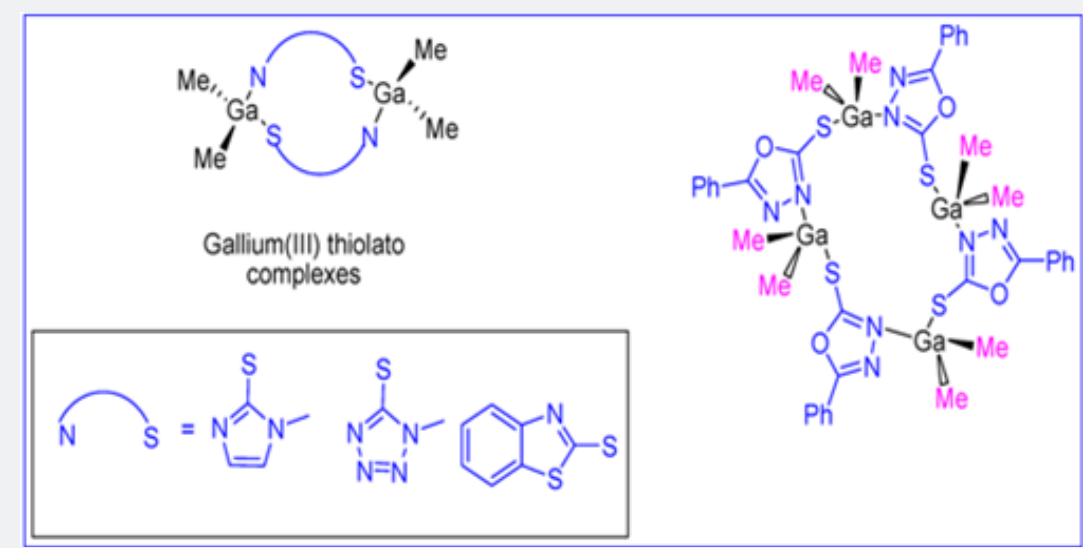

Figure 4: Heterocyclic thiolate polynuclear gallium(III) derivatives with anticancer activity.

Numerous other studies have been reported for metal complexes as medicinal agents. The use of zinc applied topically to promote the healing of wounds dates to around 1500 B.C., and silver is now commonly applied to prevent infection in bum patients. Osmium carbohydrate polymers have been reported to have anti-arthritic activity. Transition metal complexes have a long history of use as antibacterial and antiviral agents; for example, $\mathrm{Zn}$ is used to treat herpes, possibly by inhibiting the viral DNA polymerase. Early transition-metal (e.g., tungsten) polyoxoanions have been employed to treat AIDS patients. Deficit of essential metal ions leads to various deficiency syndromes that can often be fatal. Malnutrition can be treated temporarily or over longer time periods using dietary supplements consisting of one or more metal ions. Iron deficiency is the most prevalent and more than 2 billion people are affected by it worldwide. Certain metal deficiencies arise from genetic 


\section{Cancer Therapy \& Oncology International Journal}

metabolic disorders (acrodermatitis enteropathica, Menkes disease) while others occur because of complications in cases of gastric atrophy or chronic kidney disease. Acrodermatitis enteropathica is an autosomal recessive metabolic disorder affecting the uptake of zinc for which patients depend lifelong on zinc supplements to survive. Similarly, Menkes Disease is caused by a mutation on the gene encoding $\mathrm{Cu} 2+$ transporting ATPase that leads to the dysfunction of many copper dependent enzymes and acute copper deficiency. Immediate treatment can prevent brain damage.

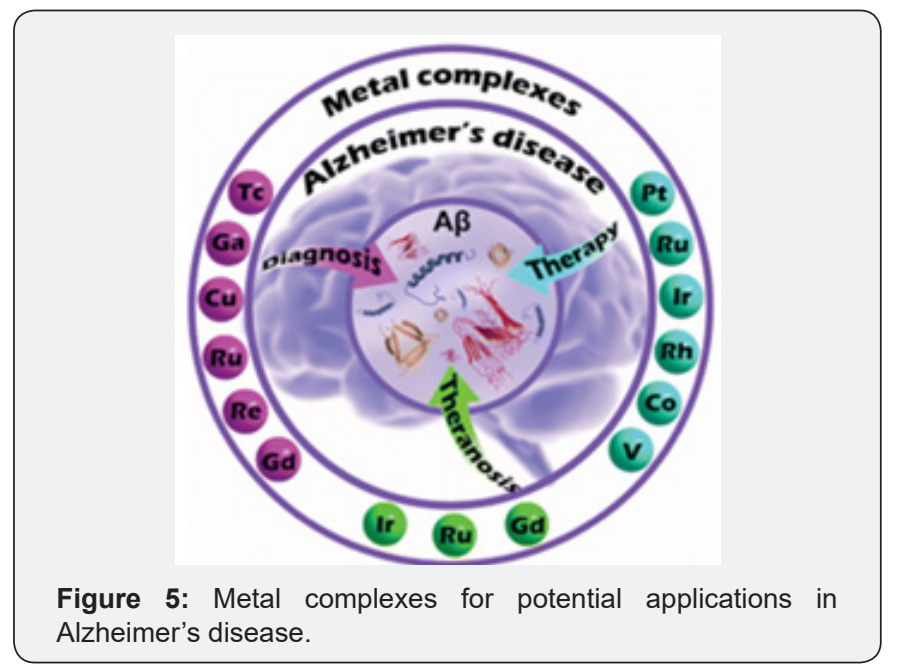

\section{Medical Use of Metal Nanoparticles}

Nanotechnology has greatly enhanced drug delivery system to a large extent, thereby reducing the unwanted effects by limiting the drug effect to specific site and leaving other tissues untouched. Therefore, the opportunity provided by nanoparticles to selectively target cancer cells and leave behind healthy cells untouched has gained interest in the design of metal-based cytotoxic drugs. Metal-based NPs are of different shapes and sizes and have been investigated for their role in diagnosis and drug delivery system. Most commonly available metal-based NPs include nickel, gold, silver, iron oxide, gadolinium and titanium dioxide [27]. Metal-based NPs provide a large surface area that allowed incorporation of large drug dose. To improve the specificity in the diagnosis of cancers, various types of highly specific and highly sensitive NP-based optical imaging platforms are being investigated [28]. They offer a major advantage compared with other agents. They can be functionalized to specifically target tumor cells, allowing the imaging and therapeutic agent to be specifically delivered to these cells.

Metal nanoparticles (silver and gold) are widely used in cell imaging, DNA hybridization detection, proteins interaction, and photothermal therapy due to their extremely strong absorption and light scattering in the plasmon resonance [29]. Among all types of noble metal-based nanoparticles, gold nanoparticles (Au NPs) have shown a great capacity for use as potential drug delivery carriers (Figure 6). It is relatively easy to obtain Au NPs with various sizes (1-100 nm) and shapes (spherical, rod-like, cage-like, etc.) [30].

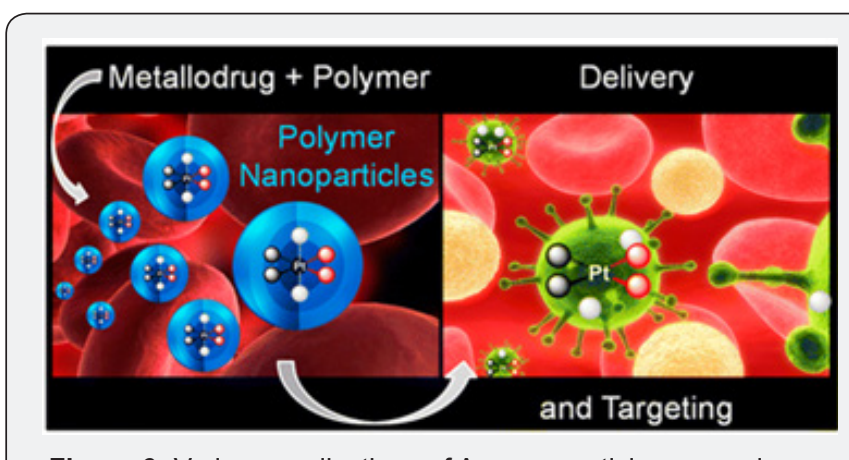

Figure 6: Various applications of Au nanoparticles as carriers.

Encapsulation of the platinum (IV) prodrug mitaplatin in block copolymer nanoparticles increases drug circulation time in the blood and reduces accumulation in the kidneys, as reported by Lippard and colleagues (Figure 7) [31]. Importantly, controlled drug release from the nanoparticles produces longterm anticancer efficacy, with the prospect of reduced side effects. Metal coordination complexes offer the prospect of novel mechanisms of activity on account of their unique architectures, as well as potential activation mechanisms, including ligand substitution and metal- and ligand-cantered redox properties.

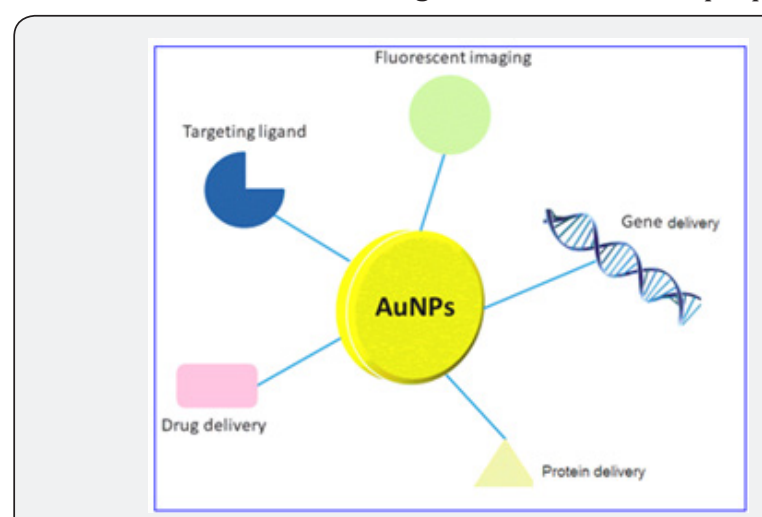

Figure 7: Encapsulated Platinum(IV) prodrug mitaplatin in block copolymer nanoparticles.

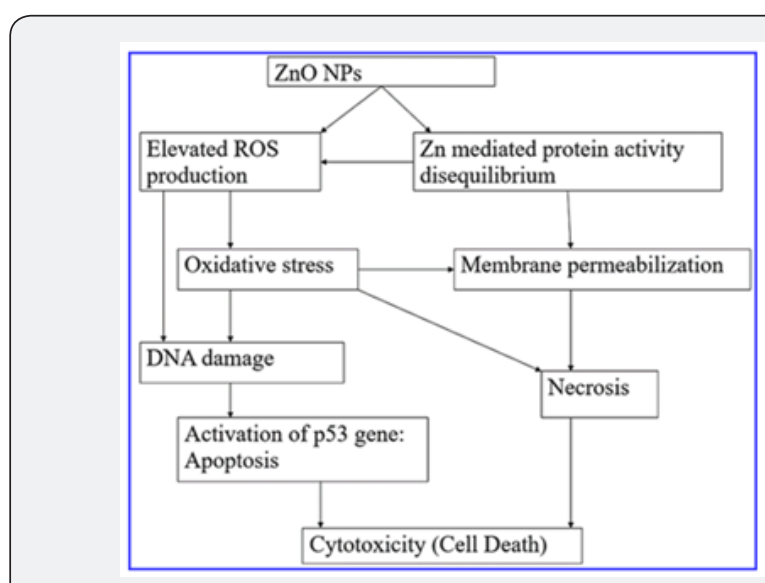

Figure 8: The use of magnetic nanoparticles embedded into PLGA nanoparticles for diagnosis and treatment of diseases. 


\section{Cancer Therapy \& Oncology International Journal}

In a recent study, antibody-conjugated magnetic poly (D, L-lactide-co-glycolide) (PLGA) nanoparticles with doxorubicin (DOX) were synthesized for the simultaneous targeted detection and treatment of breast cancer. DOX and magnetic nanoparticles were incorporated into PLGA nanoparticles, with DOX serving as an anticancer drug and Fe203 nanoparticles used as an imaging agent (Figure 8) [32].

Research has shown that low zinc concentration in cells leads to the initiation and progression of cancer and high zinc concentration shows toxic effects. The selective localization of $\mathrm{ZnO}$ nanoparticles towards cancer cells due to enhanced permeability, retention effect and electrostatic interaction show that $\mathrm{ZnO}$ nanoparticles can selectively target and kill cancer cells, making them a promising anticancer agent (Figure 9). The traditional organic drugs alone may not be complete without a parallel exploration of metal pharmacology as many organic drugs require interactions with metals for activity. Metal compounds offer new properties that cannot be found amongst purely organic agents.

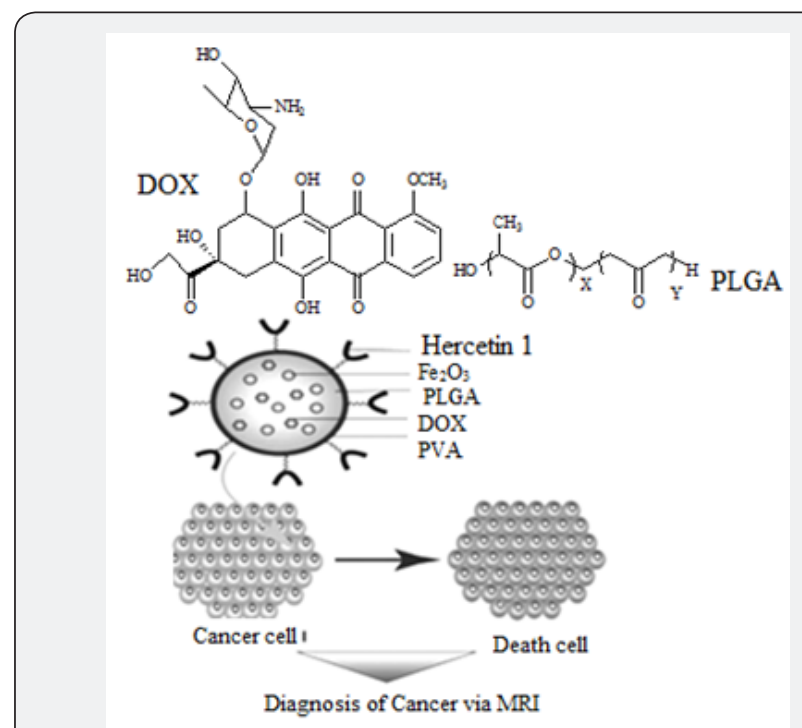

Figure 9: A schematic representation of the overall cytotoxicity of $\mathrm{ZnO}$ nanoparticles, leading to cell death

\section{Conclusion and Future Prospective}

Since metals are endowed with unique properties that are absent in conventional carbon-based drugs, the positive trend in drug discovery can be continued for the design of new metal-based drugs. The therapeutic application of metal complexes is still an unexplored area of research and may be useful to develop novel therapeutic agents. The exploration of transition metal complexes, as well as targeting and activation strategies, should lead to future generations of drugs which can overcome some of the disadvantages associated with present drug therapies, including the reduction of side-effects, widening the spectrum of activity, and resistance. The field of medicinal inorganic chemistry and interdisciplinary researches related with metallodrug should, therefore, be exploited with a rapid acceleration to solve the biological and pharmacological profiles and molecular activity mechanisms of metallodrugs in the complex biological systems. Thus, metallodrugs will certainly take a key part of drug development to improve the quality of life of patients.

\section{References}

1. Orvig C, Abrams MJ (1999) Medicinal inorganic chemistry: introduction. Chem Rev 99(9): 2201-2204.

2. Yaman M, Kaya G, Yekeler H (2007) Distribution of trace metal concentrations in paired cancerous and non-cancerous human stomach tissues. World J Gastroenterol 13(4): 612-618.

3. Warra AA (2011) Transition metal complexes and their application in drugs and cosmetics - A Review J Chem Pharm Res 3(4): 951-958.

4. Frezza M, Hindo S, Chen D, et al. (2010) Novel metals and metal complexes as platforms for cancer therapy. Curr Pharm Des 16(16): 1813-1825.

5. Yan YK, Melchart M, Habtemariam A, Sadler PJ (2005) Organometallic chemistry, biology and medicine: ruthenium arene anticancer complexes. Chem Commun 14(38): 4764-4776.

6. Salga MS, Ali HM, Abdulla MA, Abdelwahab SI (2012) Acute oral toxicity evaluations of some zinc (II) complexes derived from 1-(2-Salicylaldiminoethyl) piperazine schiff bases in rats. Int J Mol Sci 13(2): 1393-1404.

7. Haas KL, Franz KJ (2010) Application of metal coordination chemistry to explore and manipulate cell biology. Chem Rev 109(10): 4921-4960.

8. C F Shaw CF (1999) Gold-based therapeutic agents. Chem Rev 99(9): $2589-2600$

9. Allardyce CS, Dyson PJ (2016) Metal-based drugs that break the rules. Daltan Trans 45(8): 3201-3209.

10. Sun RW, Ma DL, Wong ELM, Che CM (2007) Some uses of transition metal complexes as anti-cancer and anti-HIV agents. Dalton Trans 43: 4884-4892.

11. Zhang P, Sadler PJ (2017) Redox-Active Metal Complexes for Anticancer Therapy. Eur J Inorg Chem 12: 1541-1548.

12. Yoshimoto S, Sakamoto K, Wakabayashi I, Masui H (1992) Effect of chromium administration on glucose tolerance in stroke prone spontaneously hypertensive rats with streptozotocin -induced diabetes. Metabolism 41(6): 636-642.

13. Subasinghe S, Greenbaum A.L, McLean P (1985) The insulin-mimetic action of Mn2+: involvement of cyclic nucleotides and insulin in the regulation of hepatic hexokinase and glucokinase. Biochem Med 34(1): 83-92.

14. Ozcelikay AT, Becker DJ, Ongemba LN, Pottier AM, Henquin JC, et al. (1996) Improvement of glucose and lipid metabolism in diabetic rats treated with molybdate. Am J Physiol 270(2 Pt 1): E344-52.

15. Sitasawad S, Deshpande M, Katdare M, Tirth S, Parab P (2001) Beneficial effect of supplementation with copper sulfate on STZdiabetic mice (IDDM). Diab Res Clim Pract 52(2): 77-84.

16. Walter PL, Kampkötter A, Eckers A, Barthel A, Schmoll D, et al. (2006) Modulation of FoxO signaling in human hepatoma cells by exposure to copper or zinc ions. Archives of Biochemistry and Biophysics 454(2): 107-113.

17. Ybarra J, Behrooz A, Gabriel A, Koseoglu MH, Ismail-Beigi F (1997) Glycemia-lowering effect of cobalt chloride in the diabetic rat: increased GLUT1 mRNA expression. Mol Cell Endocrinol 133: 151-160. 


\section{Cancer Therapy \& Oncology International Journal}

18. May JM, Contoreggi CS (1982) The mechanism of the insulin-like effects of ionic zinc. J Biol Chem 257(8): 4362-4368.

19. Sakurai H, Tsuchiya K, Nukatsuka M, Sofue M, Kawada J (1990) Insulinlike effect of vanadyl ion on streptozotocin-induced diabetic rats. J Endocrinol 126(3): 451-459.

20. Meyerovitch J, Farfel Z, Sack J, Shechter Y (1987) Oral Administration of Vanadate Normalizes Blood Glucose Levels in Streptozotocin-treated Rats. J Biolchem 262(14): 6658-6662.

21. Shechter Y, Karlish SJ (1980) Insulin-like stimulation of glucose oxidation in rat adipocytes by vanadyl (IV) ions. Nature 284(5756) 556-558.

22. Heyliger CE, Tahiliani AG, McNeill JH (1985) Effect of vanadate on elevated blood glucose and depressed cardiac performance of diabetic rats. Science 227(4693): 1474-1477.

23. Reul BA, Amin SS, Buchet JP, Ongemba LN, Crans DC, Brichard SM (1999) Effects of vanadium complexes with organic ligands on glucose metabolism: a comparison study in diabetic rats. Br J Pharm 126(2): 467-477.

24. Ellahioui Y, Prashar S, Gómez-Ruiz S (2017) Anticancer Applications and Recent Investigations of Metallodrugs Based on Gallium, Tin and Titanium. Inorganics 5: 4 .
25. Liu H, Qu Y, Wang X (2018) Amyloid $\beta$-targeted metal complexes for potential applications in Alzheimer's disease. Future Med. Chem 10(6): 679-701.

26. Díaz MR, Vivas-Mejia PE (2013) Nanoparticles as drug delivery systems in cancer medicine: emphasis on RNAi-containing nanoliposomes. Pharmaceuticals (Basel) 6(11): 1361-1380.

27. Ventola CL (2012) The nanomedicine revolution: part 2: current and future clinical applications. P T 37(10): 582-591.

28. Khlebtsov NG, Dykman LA (2010) Optical properties and biomedical applications of plasmonic nanoparticles. J Quant Spect Rad Trans 111(1): 1-35.

29. Kebowski B, Depciuch J, Parlinska-Wojtan, Baran J (2018) Applications of Noble Metal-Based Nanoparticlesin Medicine. Int. J Mol Sci 19(12): 4031.

30. Barry NPE, Sadler PJ (2013) Challenges for Metals in Medicine. ACS Nano 7(7): 5654-5659.

31. Nasimi P, Haidari M (2013) Medical Use of Nanoparticles: Drug Delivery and Diagnosis Diseases. International Journal of Green Nanotechnology 1: 1-5.

32. Bisht G, Rayamajhi S (2016) ZnO Nanoparticles: A Promising Anticancer Agent. Nanobiomedicine 3: 9

\section{Your next submission with Juniper Publishers will reach you the below assets}

- Quality Editorial service

- Swift Peer Review

- Reprints availability

- E-prints Service

- Manuscript Podcast for convenient understanding

- Global attainment for your research

- Manuscript accessibility in different formats

( Pdf, E-pub, Full Text, Audio)

- Unceasing customer service

Track the below URL for one-step submission https://juniperpublishers.com/online-submission.php 